\title{
The Design And Implementation Of A Strategic Plan In Primary Schools
}

Chris van Wyk, North-West University, South Africa

B. G. Moeng, North-West University, South Africa

\begin{abstract}
Many policies, strategies and plans have been introduced in South African schools so as to acquire quality education. A strategic plan, as a mechanism of putting schools on a pathway of development and effectiveness over a period of time, is one of these initiatives. Its introduction is based on a number of reasons inter-alia - the shift to school self-management, the introduction of Norms and Standards, and the introduction of School Governing Bodies (SGBs).

A school's strategic plan is the physical document that embodies the guiding orientation regarding how to manage the school within a larger national and local development perspective. Such a plan can lead to school effectiveness, improvement and development strategies, but not all plans obtain this status because of design efficiencies.
\end{abstract}

A qualitative investigation was done in two primary schools in the Mahikeng Area Office (AO) of the North-West Province in South Africa. Document analysis, in-depth interviews with two principals and two SGB chairpersons, as well as a focus group interview with eight teachers from participating schools, were used to collect data on how primary schools in question design and implement their strategic plans.

The investigation seems to suggest that, while an individual school community may craft a strategic plan in its own way, there are common aspects that underpin the entire process. Amongst others, technical knowledge and skill for its execution are necessary. Some policies emphasise the importance of a strategic plan and serve as an integrated implementation framework for its execution.

It is concluded that a strategic plan is designed and implemented under three main elements: 1) strategic analysis, which is made up of stakeholder involvement; 2) strategic choices made up of direction-setting, priority determinations, mission, and vision; and 3) strategy in action, which refers to the process of translating the plan into action.

Keywords: Strategic Plan; Design; Implementation; Education; Management; Leadership

\section{INTRODUCTION}

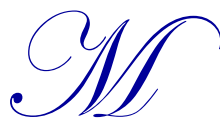

any education systems are working hard at implementing radical reforms in order to adapt to a changing world. A current international trend in education reform is the devolution of decisionmaking powers from central level to the decentralised level. In the school system, a strategic plan has been introduced as a new trend leading towards greater autonomy. It has evolved due to the need for schools to become more market driven rather than remain as a public service. This reform initiative rests on the assumption that schools are able to develop the capacity to manage their own activities. Self-management depends on, and is closely linked to, the adoption of a strategic plan for the execution of their leadership and management practices (Thurlow, Bush \& Coleman, 2003).

The introduction of a strategic plan in the school system emanated when the government realised that schools only focus on short-term tasks. Strategic decisions were taken outside the schools by external stakeholders 
and this created a culture of dependency. Amongst others, schools were at the receiving end and there was no progress. Schools did not own any decision. An approach of compliancy in schools was vibrant and this led to poor delivery (RSA, 1996). Furthermore, there is an emerging international trend toward school self-management, and South African schools have become part of this trend. Secondly, the provincial departments of education do not seem to be favourably positioned to provide adequate support and monitoring at school level (Thurlow et al., 2003).

Designing a strategic plan demands a deep understanding of what a school intends to achieve. Therefore, schools should be able to distinguish between planning for school improvement, innovation or change, and simply planning for the management aspects which would amount to operational planning. The purpose of a strategic plan is to introduce change successfully, minimise management crises, and strengthen partnerships between governance and professional staff (DoE, 2006).

\section{PROBLEM STATEMENT}

In the South African school system, new educational policies and investigations undertaken by the DoE, such as the Report of the Task Team on Education Management Development (DoE, 1996) and legislation, such as SASA 1996, focus on the need for all stakeholders in education to work in democratic and participative ways (RSA, 1996). At the core of these initiatives is a process of decentralizing decision-making as well as a practice of democratisation in the way in which schools are governed and managed (DoE, 1996). This would infuse effective schools whereby stakeholders may participate positively toward a common goal. It is only through a strategic plan that a school can be effective because it helps to identify and express goals, key improvement strategies, action plans and, finally, monitor and evaluate the school's progress for the purpose of change management. Furthermore, schools' strategic plans can contribute to the quality of planning, reporting, and accountability in the school system, something which is still a challenge in most primary schools (RSA, 1996; Molale, 2007; DoE, 2006).

A strategic plan represents a radical culture shift for schools that previously focused on short-term tasks and adopted a culture of dependency. It focuses on long-term leadership and a proactive management style, which require decision-making to be done at school level by all stakeholders in order to align their policies and practices to national and provincial legislation (Van Niekerk \& Van Niekerk, 2006). However, the Monitoring of School Readiness Report compiled by the North West Provincial Department of Education (NWPDoE, 2008) highlights that there is only limited empirical evidence of how primary schools design and implement their strategic plans. Most schools are apparently not prepared for the re-opening at the beginning of the years since policies and strategic plans, which are critical for this purpose, were, in most cases, not available and even not done timeously and correctly (NWDoE, 2008).

The following research questions were used to guide the investigation:

1. What is the nature of a strategic plan in primary schools?

2. Which processes do primary schools, in actual fact, follow to design and implement this plan?

3. What importance does the plan possess for primary schools?

4. What is the role of stakeholders in the process of applying a strategic plan?

The aim of the research reported in this article was to provide answers to these research questions. It is imperative that the theoretical framework is outlined, which is followed by an exposition of the research methods applied. The findings are thereafter discussed. The article concludes with several recommendations and a conclusion.

\section{THEORETICAL FRAMEWORK}

A strategic plan is a fairly new trend in schools leading toward greater autonomy. It has evolved due to the need for schools to become more market driven rather than remaining in a public service mode. In South African school systems, there are factors contributing to the introduction of strategic planning in schools. Firstly, the policies on Whole School Evaluation (WSE), Integrated Quality Management System (IQMS), Education Management Development and Governance (EMDG), and Norms and Standards for School finance (NNSF) draw the attention of 
schools to the importance of crafting the school strategic plan that can serve as an integrated implementation framework for policy implementation. Strategic planning can be used as the main mechanism for holding schools accountable for their overall performance. The purpose of school development, as conceptualised in policy, is to define the strategic direction of each school within a nation's policy context. Furthermore, employment of this plan allows all the leaders of an organisation to have a coherent and inclusive approach since it puts the involvement of a staff as a requirement in the long, medium and short-term planning. This plan is often seen as a key strategy in a broader move toward devolution of responsibility to the school. It adopts a holistic and integrated approach to all school operations, not just teaching and learning. The strategic planning and process is both inward and outward looking, therefore positioning the school in relation to the changing external environment. Lastly, the three theories of education change; i.e., school effectiveness, school improvement and school development, continue to use school development planning as the basis for improving performance.

A strategic plan is a living document that includes policy direction, implementation strategies, actions and benchmarks for implementation, monitoring and evaluation, as well as the expenditure framework which allows adjustments in areas for developments during implementation (Chang, 2008). It is a systematic, collaborative and inclusive plan designed by a school to promote school effectiveness, school improvement, staff development, partnerships, effective resource development, change management, and the furtherance of aims and priorities of the national education system (Xaba, 2006). Its intentions are to provide a framework for managerial decisions and to create a flow of competitive advantages that form coherent strategic leadership. Furthermore, it ensures that the learners receive quality education in terms of holistic development and academic achievement. This plan entails the school's analysis of its areas for development, prioritisation, planning to address such areas and, finally, implementing a plan to address these identified areas for development.

For this purpose, crafting a strategic plan can be a complicated process; therefore, models and/or steps to be followed exist for its success. Maximising the involvement and participation of stakeholders for the development of a strategic plan is an initial stage. During this stage, a short workshop is needed for the purpose of preparing a ground for effective participation. SWOT analysis, as the second step, assists schools in discovering their identity through external and internal assessment. Through SWOT analysis, stakeholders brainstorm on their core existence, performance and resources. The success of SWOT analysis depends on having decision-making authority in the areas of budget, curriculum and personnel to create meaningful change in teaching and learning (Clarke, 2007).

Developing vision and mission as the next step should be a collective approach to encourage a sense of ownership and maximum participation. It is the role of the school leaders to mobile stakeholders to realise that the vision and mission statements are practical and attainable. Beyond the development of both the vision and mission statements, it is important to put them on the letterhead or bill board (Molale, 2007).

Auditing as another step is also necessary to be conducted. The objective of this stage is for the schools to identify and prioritise their needs. To execute this exercise, the schools must have a checklist which might be long, so it will be necessary to construct a priority list. According to Molale (2007), priorities must be related, must have educational value, and must be justified on educational grounds.

Developing a priority list, whereby schools are engaged in goal-setting, should also be considered. DoE (2011) points out that goals are inspirational statements that define which student outcomes the schools are striving to achieve in the areas of student learning, engagement, well-being, pathways and transitions. Setting goals should be determined by long, medium, and short-term activities. To be more explicit, this will be reflected from strategic goals to specific goals; that is, by outlining strategic goals, objectives, output and outcomes.

The merit of a strategic plan can be turned into tedious work if there are no clear mechanisms to realise strategic goals. Hence, developing an action plan as the seventh step is necessary. The aim of an action plan is to bring key issues within a strategic plan. Hence, amongst others, the following elements need to be spelled out in an action plan - specific targets, key improvement strategies, timeline, resources, responsible person, and performance indicators.

Well-developed action plans would assist schools in identifying the steps necessary for reaching their goals in the most efficient way and in guiding the stakeholders toward the implementation of targets (Shapiro, 2010). 
Setting targets may be referred to identifying problems. This process requires schools to be realistic and simple and allow stakeholders to participate with understanding. Key improvement strategies represent the school's action plans. They assist schools in having a logical understanding of connected steps or high-level actions that need to be put into place to achieve improvement. It is necessary to attach a timeline in an action plan; that is, the specific dates for the execution of activities. To ensure progress, resources needed must be allocated directly to the improvement strategies planned to facilitate the goals set. This refers to financial, physical and human resources needed for each activity to be performed. There are different individuals or teams to be the driving forces toward goals achieving; therefore, persons responsible to carry out activities need to be indicated. Lastly, performance indicators should be indicated to measure the progress toward achievement of the set targets through implementation. This will evaluate the success and effectiveness of actions.

Implementation as the eighth step requires schools to establish annual objectives, devise policies, motivate employees, and allocate resources so that formulated strategies can be executed (David, 2011). Implementing strategy entails mobilising employees and managers to put into action the formulated strategies. Implementation proceeds through the vehicles of monitoring and evaluation, which assesses not only whether targets have been achieved, but also concentrates on how far the structural changes, staff development, and support from senior staff will be needed to build the capacity to implement plans (Middlewood \& Lumby, 2007).

The rationale behind a strategic plan is not likely to be accomplished unless monitoring and evaluation, as another step, is conducted. It is through this step that schools can establish areas for development make alterations and build on some good lessons. Chang (2008) defines monitoring as a process whereby the progress of activities is regularly and continuously observed and analysed in order to ensure that the expected result is achieved. It is done by regular collection and analysis of information for checking the performance of the programme activities.

Designing and implementing strategic plans rely heavily on stakeholder participation. According to Middlewood \& Lumby (2007), all stakeholders at school level should be involved in the strategic planning processes so as to achieve a coherent vision and collegial culture. Determining the participation of stakeholders should be based on three rules of thumb; that is, jurisdiction, relevance, and expertise (Middlewood \& Lumby, 2007). In terms of jurisdiction, it is important to involve those with official roles and responsibility. Relevancy should be based on the power vested in professional and governance structures.

\section{RESEARCH DESIGN AND METHODOLOGY}

The aim of the research was to examine and explore how primary schools design and implement their strategic plans. An empirical qualitative investigation that attempted to identify how primary schools design and implement strategic plans was conducted in line with research principles, as explained by authors such as De Vos (2006), Creswell (2007) and Maree (2010). A case study strategy was used and interviews were employed as qualitative data collection techniques.

\section{Data Collection Techniques}

Semi-structured interviews, a focus group interview, and an analysis of documents were identified as most suitable data collection techniques. The semi-structured interviews were conducted with principals and SGB chairpersons to obtain their views, ideas, opinions, and understanding of a strategic plan (Maree, 2010). A common interview schedule was used for all participants regardless of their constituency.

A focus group interview was conducted with teachers in a permissive and non-threatening environment. Participants were selected according to the normal procedures that apply to focus group interviews (De Vos, 2006). In total, eight teachers participated in this interview.

To ensure triangulation, we used documentary analysis. Documents were used to complement interviews and to enhance accountability, and, as such, were not necessarily analysed in detail to enhance substantive evidence. The main documents analysed were The EMDG Training Manuals, WSE reports, annual plans, and strategic plans from sampled schools. For ethical reasons, access to documents and records were negotiated in advance (Henning, 2007). 


\section{Data Analysis}

An interpretive approach was used in examining meaningful and symbolic content of qualitative data (Maree, 2010). Content analysis is the process of organising, identifying, coding, categorizing, classifying, and labelling the primary patterns in the data. Interviews were transcribed and coded and responses were grouped according to their question numbers. We were then enabled to determine what participants thought about each question and to gauge their views by doing manual analysis of the relevant data.

\section{Sample and Information of the Two Case Study Schools}

The research was conducted in the North West Province - one of the nine provinces in South Africa. Ngaka Modiri Molema is one of the four districts in the province. This district has five Area Offices (AOs) and Mahikeng $\mathrm{AO}$, where the research was conducted, is one of them. This Area Office was chosen due to convenience as one of the researchers is based in Mahikeng and working in the provincial Education Department at Quality Assurance Chief Directorate.

Two schools - called School A and School B - from Mahikeng AO primary schools were selected on the ground of their accessibility. Both schools and participants were deemed to be information rich with respect to the purpose of the study due to the following reasons. The schools are situated in a rural area and regarded as big primary schools because their learners' enrolments are above 1,000. The principal at school A is a male who has been in the principal-ship post for twelve years. At school B, the principal is a female and has been in the post for eight years. The illiteracy level and socio-economic status of both communities being served by the schools are poor. Both schools obtained Section 21 or self-managing status under the SASA of 1996. They both have undergone the WSE-programme that forms part of strategic planning and includes a SWOT-analysis.

\section{RESEARCH FINDINGS}

The process of executing strategic plans is a complex change. Related to this, there is sufficient empirical evidence which points to the extent that the beneficiaries of strategic plans can be frustrated due to the failure of proper implementation processes followed. The results of this investigation indicate that schools still confuse strategic plans with School Improvement Plans (SIP). There is an indication that these schools find it difficult following models or templates suggested by EMDG Training Manuals and other books on the steps to design and implement strategic plans. Both participating schools are, however, in possession of strategic plans they had designed, but they did not follow any template or model suggested by some authors, such as Jonson et al. (2006), or even the EMDG Training Manuals developed by DoE. The strategic plans they have were designed for a three-year period and, at this stage, there is little confidence in planning further ahead.

Time frames are not specific and performance indicators are not included. Due to the fact that performance indicators were not indicated, they were not able to conduct the review process properly. Furthermore, the operational plans for the second and third years could not be linked to the strategic plans.

The study also revealed that the understanding of the processes of strategic planning needs advanced technical skills and knowledge; hence, intensive training for all role-players is a requirement. It has been found that stakeholders' participation is also a key to the success of strategic planning, but only SMTs and SGBs were trained in the two schools. Furthermore, the training manuals are written in English, which does not consider community members that might have language barriers. In this regard, it was also noted that although the role of departmental officials at different levels is crucial, neither of the schools received the kind of support from the department on strategic planning they are entitled to. This might suggest that the nature, framework, procedures, and importance of strategic plans are still not well understood by the major stakeholders.

The importance of strategic plans in schools is drawn by some policies, such as WSE, IQMS, EMDG and NNSF, but schools seem to treat them as loose-standing documents. Treating these policies in this manner created confusion in the two schools whereby each policy is implemented on its own. 
It was also found that the process of a SWOT analysis is not as well understood as it should be because the main stakeholders do not attend meetings in their different structures. Therefore the technical part of a SWOT analysis becomes the task for professional staff only. The understanding of different types of planning has also been found to be a challenge since neither of the two schools could differentiate annual/operational plans from strategic plans.

\section{DISCUSSION}

The efficient implementation of a strategic planning process is based on having in place a well-functioning and integrated system and on obtaining effective participation by all relevant stakeholders. A wide range of policies form part of the current system. Amongst these are WSE, IQMS, EMDG, and NNSF. These policies are obviously not implemented in an integrated manner. It seems that stakeholders are even confused by the "different messages sent out" by these documents and that some of the policies and practices developed by the DoE impact negatively on the strategic planning process. All policies should be appraised and revised where necessary. The cycle of strategic plans should be in accordance with the election of SGBs and the WSE cycle and then be linked with other relevant policies. This will ensure that one of the roles of SGBs, as stipulated by SASA, which is crafting a school's strategic plan, is catered for properly.

The challenge of low level of participation from stakeholders, especially parents, is another main concern that must be addressed. Parental involvement depends, to a large degree, on how well they are trained. In this regard, departmental officials, as well as SMTs, have an important role to play. Apart from being implemented correctly, training manuals that guide schools on the process of strategic plans should be in the local vernacular. This will accommodate those with language barriers and improve understanding of the whole process. Secondly, all stakeholders should be trained on the process of strategic planning and not just SMTs and SGBs.

Designing and implementing a strategic plan depends entirely on several factors, such as communication skills, availability of resources, attitudes, and defined roles played by different stakeholders; therefore, it is necessary for the department to ensure that these are well catered for in the major strategic planning of 21century priorities.

\section{CONCLUSION}

The process of strategic planning is arguably more important than simply providing the document itself. Therefore, the effectiveness of the strategic planning process is best measured by the extent to which all stakeholders understand their roles. The responsibility for strategic planning lies with the school principals, in collaboration with school staff, and further requires that SGBs take part in establishing and reviewing their schools strategic plans. This collaborative approach to strategic planning requires that schools develop a planning process that is consultative, inclusive, and coherent. It is clear that this process cannot be solely and simply located in the SGB domain of functions; therefore, the principal and other SMT members should be responsible for initiating and monitoring the process. This suggests the intensive management development to assist principals and SMTs to understand different types of planning. Again, the departmental officials responsible for this function should be skilled and knowledgeable to support the process.

\section{AUTHOR INFORMATION}

Professor Chris van Wyk is a senior academic with 35 years of experience at Tertiary Education institutions. He publishes articles on a regular basis and is responsible for a number of Masters and Doctorate students. E-mail: vanwyk.christo@nwu.ac.za (Corresponding author)

Ms. Boitumelo Gloria Moeng obtained her University Diploma in Primary Education in 1992 and taught at GAIsrael Primary school from February 1993 to 1999. She was promoted to Deputy Principal during 2000 and became a departmental researcher in the Quality Assurance Directorate of the North West Department of Education in November 2007. She obtained her Masters Degree in Educational Management in 2012. E-mail: bmoeng@nwpg.gov.za 


\section{REFERENCES}

1. Bush, T., Coleman, M., \& Thurlow, M. (2003) .Theory and practice in educational Management. In Leadership and Strategic Management in South African schools. London: The Commonwealth Secretariat.

2. Chang, G. C. (2008). Strategic planning in Education: Some concepts and methods. Paris: UNESCO.

3. Clarke, A. (2007). A handbook for school management and leadership. Cape Town: Kate McCallum.

4. Creswell, J. W. (2007). Qualitative inquiry and research design. Choosing among five approaches (2nd ed.). Thousand Oaks. California: Sage.

5. David, F. R. (2011). The strategic management: Concepts and cases (9th ed.). Prentice Hall. Pearson Education.

6. De Vos. (2006). Research at grass roots. The social sciences and human science professions. Pretoria: Van Schaik.

7. Henning, E., Van Rensburg, W., \& Smit, B. (2007). Finding your way in qualitative research. Pretoria: Van Schiak.

8. Halladay, D. (2008). School strategic planning. How to ensure success. Somerville: Cape Town The Grammar School.

9. Maree, K. (2010). First steps in research. Pretoria: Van Schaik.

10. Middlewood, S., \& Lumby, M. (2007). Strategic management in schools and colleges. London: Paul Chapman.

11. Molale, I. S. (2007). How policy travels? An insight into the politics of implementation (1st ed.). Mafikeng: Mosipidi Management.

12. Mcube, V. S. (2007). Social justice, policy and parents' understanding of their voice in school governing bodies in South Africa. Journal of Educational Administration and History, 39(2), 129-143

13. North West Department of Education (2007). Management of governance training manual for school management and school governing bodies. Mahikeng: Government Printers.

14. Nieuwenhuis, J. (2010). Qualitative research designs and data gathering techniques. Pretoria: Van Schaik.

15. The Republic of South Africa (1996). Report of the task team on education management development. Pretoria: Government Printers.

16. Republic of South Africa (1996). South African Schools Act, 84 of 1996. Government Gazette, 337 (17579). Pretoria: Government printers.

17. Shapiro, J. (2010). Toolkit on overview of strategic planning. Washington: Olive Publication. Retrieved from http://www.civicus.org

18. Van Niekerk, E. J., \& Van Niekerk, P. (2006). Strategic management in South African education: The leadership dimension. Africa Education Review, 3(1), 84-99.

19. Wheelen, T. L., \& Hunger, D. J. (2008). Strategic management and business policy: Concepts and cases (11th ed.). Pearson Prentice Hall: Upper Saddle River.

20. Xaba, M. (2006). The difficulties of school development planning. South African Journal of Education, 26(1), 15-26. 


\section{NOTES}

